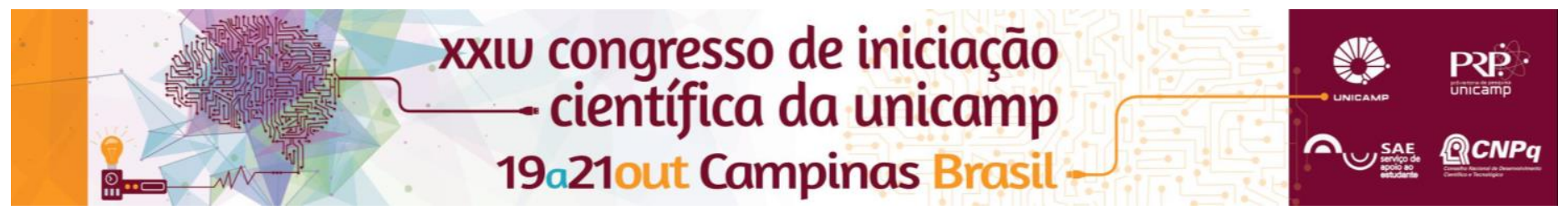

\title{
ADOÇÃO DE NOVOS SISTEMAS DE PRODUÇÃO NA INDÚSTRIA DO PETRÓLEO OFFSHORE: A EVOLUÇÃO DAS TECNOLOGIAS DE BOMBEIO SUBMARINO
}

\author{
MATHEUS G. S. PERETA
}

\begin{abstract}
Resumo
O objetivo desta investigação é identificar os conceitos tecnológicos associados ao bombeio submarino que são desenvolvidos para operar em projetos de exploração e produção de hidrocarbonetos do segmento offshore da indústria do petróleo. A análise da evolução dessas tecnologias é fundamental para observar a dinâmica de inovação nesse setor de alta intensidade tecnológica, em um contexto de riscos econômicos e maiores desafios tecnológicos. Nesse sentido, enfatizamos a fase pré-competitiva do desenvolvimento tecnológico, isto é, a produção de conhecimentos tecnológicos. Assim sendo, sistematizamos um banco de dados sobre publicações e, nos apoiando na literatura sobre análise quantitativa em ciência e tecnologia, exploramos as informações sobre uma perspectiva bibliométrica. Nossos resultados indicaram que o bombeio submarino é uma aposta para superar os gargalos da exploração de hidrocarbonetos em regiões mais complexas, todavia, seu desenvolvimento tecnológico encontra grandes obstáculos operacionais que apenas o estabelecimento de cooperações e parcerias estratégicas entre as organizações pode conformar uma trajetória tecnológica dominante desses sistemas de produção.
\end{abstract}

\section{Palavras-chave}

Inovação tecnológica, Indústria do petróleo, sistemas subsea.

\section{Introdução}

indústria do petróleo vêm desenvolvendo, desde o início da década de 1980, novos métodos de recuperação de petróleo e gás natural capazes de aumentar a eficiência operacional desse setor em regiões geológicas mais complexas. O bombeio submarino é uma opção tecnológica que visa superar os gargalos da produção em lâminas d'água cada vez mais profundas. Todavia, os riscos de falibilidade dessas tecnologias associado ao alto custo da inovação implica na necessidade das organizações estabelecerem cooperações desde o nível pré-competitivo do desenvolvimento tecnológico a fim de produzir conhecimentos que corroborem à conformação de sistemas tecnológicos maduros no setor subsea.

O objeto de nossa análise são as publicações acerca dos conceitos de bombeio submarino, abordando-as de forma a construir indicadores de ciência e tecnologia com a finalidade de observar sua evolução tecnológica.

\section{Resultados e Discussão}

Foram levantados 111 artigos, ou trabalhos em anais de congressos na base de dados Scopus no período 1988 2015, associados aos seguintes conceitos tecnológicos, i) subsea gas compression technology; ii) subsea boosting technology; iii) subsea water injection technology; iv) subsea separation technology; v) subsea multiphase pump; vi) subsea twin-screw pump; vii) subsea helico-axial pump; viii) subsea centrifugal pump e, finalmente, ix) electrical submersible pump. A construção de indicadores de análise quantitativa dessas tecnologias deu ênfase à sua origem geográfica e institucional. Os países que mais publicam sobre o bombeio submarino são os Estados Unidos, o Brasil, a Noruega e o Reino Unidos; isto é, regiões historicamente importantes e estratégicas para o desenvolvimento da produção e de inovações tecnológicas no setor de petróleo e gás natural. Além disso, as principais organizações envolvidas com o desenvolvimento do bombeio submarino são empresas fornecedoras (49\%); companhias de petróleo (40\%) e instituições acadêmicas
(11\%). A Petrobrás é a instituição com maior número de publicações afiliadas (19), todavia, o conteúdo dos conhecimentos discutidos diz respeito a experiências com essas tecnologias ao invés de tratar do processo de desenvolvimento tecnológico das mesmas. No que diz respeito às publicações em cooperação entre diferentes organizações, a companhia brasileira não apresenta tendência em desenvolver conhecimentos colaborativamente nessa área. Ao observar a rede de cooperação de pesquisa tecnológica, temos que as companhias de petróleo e empresas fornecedoras são as que mais interagem, estabelecendo relações do tipo usuário - fornecedor.

\section{Conclusões}

A adoção em larga escala das tecnologias de bombeio submarino ainda é limitada devido à complexidade dos desafios tecnológicos que implicam a imersão a grandes profundidades de equipamentos de grande porte. A análise bibliométrica da produção tecnológica dos conhecimentos a respeito dessas tecnologias, apontou a evolução dessas tecnologias para uma fase précompetitiva da inovação. $O$ estabelecimento de cooperações de pesquisa entre as organizações é fundamental nesse processo.

\section{Agradecimentos}

Gostaria de agradecer, em primeiro lugar, ao meu orientador, o Prof. André Furtado por acreditar no meu trabalho, tornando a experiência da pesquisa muito proveitosa. Agradeço também ao PIBIC SAE-Unicamp pela concessão de uma bolsa de estudos que permitiu a realização deste trabalho.

Furtado, A.; Freitas, A.. The catch-up strategy of Petrobras through cooperative $R \& D$. In: Journal of Technology Transfer, 25, 2000. 23 - 36. 